\title{
LA PROTECCIÓN DE LOS DERECHOS HUMANOS EN LA JUSTICIA PENAL INTERNACIONAL: EL CASO PARTICULAR DEL TRIBUNAL PENAL INTERNACIONAL PARA LA EX-YUGOSLAVIA EN RELACIÓN CON EL DERECHO CONSUETUDINARIO Y EL PRINCIPIO DE LEGALIDAD
}

\author{
THE PROTECTION OF HUMAN RIGHTS IN INTERNATIONAL CRIMINAL \\ JUSTICE: THE PARTICULAR CASE OF THE INTERNATIONAL CRIMINAL \\ TRIBUNAL FOR THE FORMER YUGOSLAVIA IN RELATION TO CUSTOMARY \\ LAW AND THE PRINCIPLE OF LEGALITY
}

\author{
Elena C. Díaz Galán* y Harold Bertot Triana**
}

\begin{abstract}
RESUMEN: La labor del Tribunal Penal Internacional para la Ex-Yugoslavia tuvo un momento importante en la compresión del principio de legalidad, como principio básico en la garantía de los derechos humanos, al enfrentar no sólo el derecho consuetudinario como fuente de derecho sino también diferentes modos o enfoques en la identificación de este derecho consuetudinario. Esta relación debe ser analizada a la luz de las limitaciones que tiene el derecho internacional y, sobre todo, de los procedimientos de creación de normas. No resulta fácil exigir responsabilidad en el cumplimiento del derecho internacional humanitario y de los derechos humanos. La práctica de este Tribunal abre una vía para la reflexión con la finalidad de asegurar el respeto de los derechos humanos en cualquier circunstancia, incluso de aquellos que llevaron a cabo la comisión de graves crímenes contra la comunidad internacional.
\end{abstract}

ABSTRACT: The work of the International Criminal Tribunal for the former Yugoslavia was important for understanding the principle of legality as a key principle on the guarantee of Human Rights. The former was due to the Tribunal's work on having faced the customary law as a source of law using different perspectives for its identification. The link between customary law, principle of legality and human rights has to be analyzed taking in account the limits of International law and the procedures for creating legal norms. It is not easy to invoke responsibility in the fulfillment of international humanitarian law and international law of human rights. The practice developed by this Tribunal provides an avenue for thinking about ensuring the respect of the human rights in any case including the commission of grave crimes against international community.

PALABRAS CLAVE: derecho internacional de los derechos humanos, principio de legalidad, derecho internacional humanitario, costumbre internacional

KEYWORDS: international law of human rights, principle of legality, international humanitarian law, international custom

Fecha de recepción: 02/10/2018

Fecha de aceptación: 11/10/2018

doi: https://doi.org/10.20318/universitas.2019.4510

\footnotetext{
* Profesora de Derecho Internacional y Relaciones Internacionales. Universidad Rey Juan Carlos de Madrid, España. E-mail: elenacdiaz1@gmail.com

** Profesor de Derecho Internacional Público. Universidad de la Habana, Cuba. Email: hbertottriana@gmail.com
} 


\section{1.- INTRODUCCIÓN}

La condena del 22 de Noviembre de 2017 al militar serbobosnio Ratki Mladic ${ }^{1}$, conocido como "el carnicero de los Balcanes", a cadena perpetua por la comisión, entre otros, del crimen de genocidio ocurrido en Srebrenica en 1993, marcó la última sentencia del Tribunal Penal Internacional para la ExYugoslavia (TPIY), que funcionó durante más de veinte años, cerrando sus puertas en diciembre de 2017. Como expresó el Secretario General de Naciones Unidas António Guterres en su Remarks at Closing Ceremony for the International Criminal Tribunal for the Former Yugoslavia (ICTY), el 1 de diciembre de 2017: "The Tribunal sat for more than 10,000 days of trial, and heard testimony from nearly 5,000 people. Ninety individuals were sentenced for their crimes, including genocide, war crimes and crimes against humanity. And beyond these numbers, the Tribunal gave a voice to victims. People who had experienced atrocious violence and tragic losses, including women and girls, were given the opportunity to tell their stories in court, to place their experiences on the record, and to see the perpetrators of crimes against them held accountable. This, in itself, has contributed to the healing process"2.

El TPIY marcó un punto de inflexión en la historia del derecho penal internacional. Como manifestó el Secretario General de la ONU este Tribunal "demonstrated a new found and serious commitment by the international community that those responsible for perpetrating the most serious crimes of international concern should be held accountable for their actions", siendo "a pioneer in creating the contemporary architecture of international criminal justice". Así, "since the establishment of the Tribunal, we have seen a flourishing of entities established to ensure accountability, including the International Criminal Tribunal for Rwanda, the Special Court for Sierra Leone, the Extraordinary Chambers in the Courts of Cambodia, the Special Tribunal for Lebanon and, of course, the International Criminal Court", "also helped to inspire prosecutions and trials for international crimes at the domestic level" 3 .

El impacto y trascendencia de este Tribunal para el desarrollo y consagración de normas consuetudinarias en el ámbito del Derecho Internacional Humanitario resultaron notabilísimos ${ }^{4}$. En la actualidad,

\footnotetext{
1 Ver los cinco volúmenes de la sentencia. Prosecutor v. Ratko Mladi, Judgment, Trial Chamber I, Case No. IT-09-92-T, 22 November, 2017.

2 GUTERRES, A., "Remarks at Closing Ceremony for the International Criminal Tribunal for the Former Yugoslavia (ICTY)" de 1 de diciembre de 2017, consultar en https://www.un.org/sg/en/content/sg/speeches/2017-12-21/international-criminaltribunal-former yugoslavia-closing-ceremony

${ }^{3}$ Ibid.

4 Sobre la importancia de este tribunal para el desarrollo del derecho consuetudinario del derecho internacional humanitario, ver el papel que jugó en cada una de sus materias en: Perspectives on the ICRC study on customary
} 
no se puede construir el cuerpo de esta rama del derecho internacional, y del derecho penal internacional en general, sin tener en cuenta los aportes de este Tribunal en materias tan diversas como la definición de crímenes internacionales o la aplicación de las normas de derecho internacional humanitario tanto en conflictos armados internacionales como en conflictos armados internos. Sin embargo, resulta cierto también que la complejidad en la identificación del derecho internacional consuetudinario, en una rama del derecho internacional tan controvertida como el derecho internacional humanitario -que es extensivo al derecho Internacional en general-, una vez que se concibió como una fuente imprescindible de derecho en la labor de este Tribunal, y la aplicación y respeto del principio de legalidad, elevado a norma consuetudinario internacional gracias al impulso decisivo del derecho internacional de los derechos humanos, puso en grandes aprietos a una instancia internacional urgida de hacer justicia ante la comisión de crímenes gravísimos para la comunidad internacional.

El trabajo se enfocará fundamentalmente en el impacto que tuvo una compleja metodología en la identificación del derecho consuetudinario en el principio de legalidad por parte de este Tribunal. Con ello, se realiza el análisis en el ámbito de las garantías de los derechos de las personas procesadas que el principio de legalidad buscaba salvaguardar y proteger. En todo caso, el trabajo busca, primero, exponer y analizar las dificultades en la identificación del derecho internacional consuetudinario y la metodología utilizada por el TPIY a partir de la exposición de un grupo de casos; $y$, segundo, estudiar en perspectiva cómo esta metodología impacta en la aplicación del principio de legalidad, asumido y proclamado por este Tribunal como regulador de su actividad.

\section{2.- LA CREACIÓN DEL TRIBUNAL PENAL INTERNACIONAL PARA LA EX-YUGOSLAVIA Y EL DERECHO CONSUETUDINARIO}

El TPIY tiene causa, en palabras reiteradas del Consejo de Seguridad, en una serie de informes de "violaciones generalizadas y flagrantes del Derecho Internacional humanitario, y especialmente en la República de Bosnia y Herzegovina". Pero, también, en "informes de asesinatos en masa, de detenciones y violaciones de mujeres

international Humanitarian Law, Edited by Elizabeth Wilmshurst and Susan Breau, Cambridge University Press 2007. Ver también a BOAS, G., BISCHOFF, J.L., REID, N.L., TAYLOR III, B.D., International Criminal Procedure International Criminal law Practitioner library Series, Volume II, Cambridge university Press, 2009; ROBERTS, K., "The Contribution of the ICTY to the Grave Breaches Regime", Journal of International Criminal Justice, 7 (2009), pp.743-761. Ver igualmente el aporte del TPIY a la consolidación de disposiciones de las Convenciones de Ginebra de 1949 al derecho internacional consuetudinario. HENCKAERTS, J.M., "The Grave Breaches Regime as Customary International Law", Journal of International Criminal Justice, 7 (2009), pp. 683-701. 
masivas, organizadas y sistemáticas, y de la continuación de la práctica de "depuración étnica", inclusive para la adquisición y la retención de territorio" 5 . Entre otras muchas, por la Resolución 808 de 22 de febrero de 1993 del Consejo de Seguridad, y en uso de las facultades que le estaban conferidas en el capítulo VII de la Carta -en tanto estos hechos constituían una "amenaza para la paz y la seguridad internacionales"-, este órgano, decidió establecer un "tribunal internacional para el enjuiciamiento de los presuntos responsables de las violaciones graves del derecho internacional humanitario cometidas en el territorio del ex Yugoslavia desde 1991" y pedía al Secretario General que presentara cuanto antes para su examen por el Consejo un informe sobre todos los aspectos de esta cuestión ${ }^{6}$. Con la Resolución 827 de 1993, el Consejo de Seguridad decidió finalmente establecer dicho Tribunal y aprobó el informe del Secretario General, que contenía el Estatuto y unos comentarios jurídicos?.

El Estatuto reconocía competencia al Tribunal Internacional para juzgar a los presuntos responsables de violaciones del derecho internacional humanitario cometidas a partir de 1991 en el territorio de la ex-Yugoslavia. De modo específico, las competencias del Tribunal se fijaron en los siguientes términos: competencia ratione personae, con respecto a las personas físicas; competencia ratione loci, en lo que concierne al territorio de la antigua República Federativa Socialista de Yugoslavia, incluyendo su espacio terrestre, su espacio aéreo y sus aguas territoriales; y competencia ratione temporis, que se extendía al período que comenzaba el $1^{\circ}$ de enero de 1991. Establecía como crímenes internacionales por los cuales juzgar a los presuntos responsables las infracciones graves a la Convención de Ginebra del 12 de agosto de 1949, las violaciones de las leyes o prácticas de guerra, el genocidio y los crímenes contra la humanidad. En cuanto a las reglas y procedimientos sería un Tribunal sui generis, en tanto el propio Estatuto en su artículo 15, delegó en los propios jueces la adopción de reglas de procedimiento $^{8}$ y constituyó una mezcla de varios sistemas, cuyo "predominant structure gives deference to the adversarial common law system of criminal justice, although they depart from it in many ways. Laced

\footnotetext{
${ }^{5}$ S/Res/ 827 (1993) 25 de mayo de 1993.

${ }^{6} \mathrm{~S} / \mathrm{Res} / 808$ (1993) 22 de febrero de 1993.

7 En el asunto Tadić, el Tribunal tuvo que resolver las posiciones que apuntaban a la acción del CS al establecer el Tribunal Internacional y al adoptar el Estatuto, donde se sostenía que funcionó más allá de sus facultades y, por lo tanto, el Tribunal Internacional, no estaba debidamente establecido.

8 BOAS G., BISCHOFF, J.L., REID, N.L., Taylor III, B.D., International Criminal Procedure International Criminal law Practitioner library Series, Volume III, Cambridge university Press, 2011, pp. 23 y 24.
} 
from the start with concepts from the civil law or Romano-Germanic system of criminal procedure, the Rules have evolved through"9.

En el Informe aprobado por el Consejo de Seguridad, el Secretario General consideraba que el derecho internacional humanitario estaba conformado tanto por reglas de carácter convencional como consuetudinarias, y reconocía que la mayor parte de este derecho se formaba precisamente como derecho consuetudinario. Éste era el elemento clave, a juicio del Secretario General, para evitar la violación del principio de nullum crimen sine lege, en la medida que "the application of the principie nullum crimen sine leae requires that the international tribunal should apply rules of international humanitarian law which are beyond any doubt part of customary law so that the problema of adherence of some but not all States to specific conventions does not arise. This would appear to be particularly important in the context of an international tribunal prosecuting persons responsable for serious violations of international humanitarian law"10. Por tanto, a juicio del Secretario General el derecho internacional convencional, que había pasado a formar parte del derecho internacional consuetudinario, era el derecho aplicable a los conflictos armados como se establecía en los Convenios de Ginebra del 12 de agosto de 1949 para la protección de las víctimas de la guerra, en el Convenio de La Haya (IV) relativo a las leyes y costumbres de la guerra en tierra y el Reglamento anexo al mismo de 18 de octubre de 1907, en la Convención para la Prevención y la Sanción del Delito de Genocidio de 9 de diciembre de 1948, y la Carta del Tribunal Militar Internacional de 8 de agosto de $1945^{11}$.

Aunque el Estatuto del TPIY no tenía autorización explícita para la aplicación general de derecho internacional consuetudinario ${ }^{12}$, sirvió, en la lógica de Schabas, para delimitar el alcance de los crímenes en sí mismos sobre la base de las disposiciones derivadas de los tratados antiguos, para argumentar la no violación del principio de nullum crimen sine lege al argumentar que la ley se puede

\footnotetext{
9 BOAS, G., "A Code of Evidence and Procedure for International Criminal Law? The Rules of ICTY", International Criminal Law Developments in the Case Law of the ICTY, Boas, Gideon; Schabas William, A., editors, Martinus Nijhoff Publishers Leiden-Boston, 2003, pp. 1-34.

10 Report of the Secretary General Pursuant to Paragraph 2 of Security Council Resolution 808 (1993), S/25704 3 May 1993, United Nations, Security Council, p. 9.

${ }^{11}$ Ibid., p. 9.

12 Sin embargo, la referencia en el art. 3 del Estatuto del TPIY a las "leyes o usos de la guerra" se ha interpretado como la incorporación dentro de la jurisdicción del Tribunal de todos los delitos reconocidos como "violaciones graves del derecho internacional humanitario" en la medida en que forman parte del derecho internacional consuetudinario. SCHABAS, W., "Customary Law or "Judge-Made" Law: Judicial Creativity at the UN Criminal Tribunals", en The Legal Regime of the International Criminal Court, Essays in Honour of Professor Igor Blishchenko, Edited by José Doria Hans-Peter Gasser M. Cherif Bassiouni, Martinus Nijhoff Publishers, Leiden-Boston, 2009, p. 79.
} 
encontrar en la costumbre, aunque no se haya escrito, así como para resolver cuestiones procesales y probatorias, particularmente cuando encontraban lagunas en los textos aplicables ${ }^{13}$. En este punto, también la aplicación de principios generales del derecho internacional Penal tuvo que pasar primero la prueba de si formaban parte del derecho internacional consuetudinario, 0 más específicamente, "that to hold that a principle was part of customary international law, it has to be satisfied that State practice recognized the principle on the basis of supporting opinio juris"14.

El Tribunal aclaró que el Consejo de Seguridad podía adoptar definiciones de crímenes en el Estatuto que se apartaran del derecho internacional consuetudinario, pero entendió que, a menos que la intención de apartarse del derecho internacional consuetudinario se expresara en los términos del Estatuto 0 de otras fuentes autorizadas, como principio general, las disposiciones del Estatuto que definían los crímenes de la competencia del Tribunal debían interpretarse siempre como reflejo del derecho internacional consuetudinario ${ }^{15}$. En este sentido, la Cámara de Apelaciones del TPIY en el asunto Tadić consideró que: "The same conclusion is reached if Article 5 is construed in light of the principle whereby, in case of doubt and whenever the contrary is not apparent from the text of a statutory or treaty provision, such a provision must be interpreted in light of, and in conformity with, customary international law. In the case of the Statute, it must be presumed that the Security Council, where it did not explicitly or implicitly depart from general rules of international law, intended to remain within the confines of such rules"16.

\section{3.- PROBLEMAS ASOCIADOS A LA DETERMINACIÓN DEL DERECHO CONSUETUDINARIO}

La formación y determinación del derecho consuetudinario en el Derecho Internacional es un tema todavía pendiente para la comunidad internacional. Tanto es así que la Comisión de Derecho Internacional, en su $63^{\circ}$ período de sesiones, celebrado en 2011, decidió incluir el tema titulado "Formación y documentación del derecho internacional consuetudinario" en su programa de trabajo a largo plazo ${ }^{17}$. En 2012, en su $64^{\circ}$ período de sesiones, esta cuestión

\footnotetext{
13 Ibid, p.77.

${ }^{14}$ Prosecutor v Enver Hadzihasanovic, Mehmed Alagic and Amir Kubura, Decision on Interlocutory Appeal Challenging Jurisdiction in Relation to Command Responsibility, 16 July 2003, párrafo. 12.

15 Prosecutor v. Tadić, cit, párrafo. 296.

${ }^{16}$ Ibid, párrafo 287.

17 Ver Documentos Oficiales de la Asamblea General, sexagésimo sexto período de sesiones, Suplemento núm. $10(\mathrm{~A} / 66 / 10)$, párrs. 365 a 367 . El título del tema se simplificaría a "Identificación del derecho internacional consuetudinario" en su 65a período de sesiones, celebrado en 2013. (Documentos Oficiales de la Asamblea
} 
pasaría a formar parte del programa de trabajo actual18. Los trabajos de esta Comisión pusieron de relieve la existencia de distintos enfoques cuando se trataba de estudiar la formación del derecho internacional consuetudinario en las distintas ramas del derecho internacional (derecho internacional de los derechos humanos, el derecho penal internacional y el derecho internacional humanitario), ${ }^{19}$ y también se expresó la posible controversia sobre la actuación de los tribunales internacionales en la identificación de las normas de derecho internacional consuetudinario ${ }^{20}$.

De la práctica de la Corte Internacional de Justicia, no se puede concluir un método claro y definitivo para su identificación ${ }^{21}$. Quien fuera Presidente la Corte Internacional de Justicia, Peter Tomka, consideró que "the Court continues to be faced with questions related to the status and scope of customary rules, even as they are increasingly codified"22. Y, en tal sentido, considera Tomka que "the Court has taken a pragmatic approach to determining the existence and content of international custom, considering whether a rule has been convincingly identified before moving on to consider the primary evidence of State practice and opinio juris", ${ }^{23}$. Esto puede encontrar causa, tal vez, en inquietudes como las que expresó Allain Pellet, sobre el "misterio" y la "alquimia empírica" que preside en la Corte para "descubrir" una regla antes de aplicarla a un caso en concreto ${ }^{24}$.

A diferencia de los Tratados como fuente de derecho, en la costumbre no es fácil, en muchas ocasiones, descubrir lo que los Estados realmente hacen, y el peso que se le debe dar a sus actos puesto que algunas conclusiones normativas que se extraerán de ellos pueden ser muy controvertidas ${ }^{25}$. Desde hace algún tiempo el

General, sexagésimo octavo período de sesiones, Suplemento núm. 10 (A/68/10), párr. 65). Ver un análisis de los reportes de la CDI en: ARAJÄRVI, N., "The Requisite Rigour in the Identification of Customary International Law. A Look at the Reports of the Special Rapporteur of the International Law Commission", en International Community Law Review 19 (2017), pp. 9-46.

18 Documentos Oficiales de la Asamblea General, sexagésimo séptimo período de sesiones, Suplemento núm. 10 (A/67/10), párr. 268.

${ }^{19}$ Comisión de Derecho Internacional $65^{\circ}$ período de sesiones, cit, p. 9.

${ }^{20}$ Ibid, p. 30.

21 Ver: MENDELSON, M., "The International Court of Justice and the sources of international law", en Fifty years of the International Court of Justice, Essays in honour of Sir Robert Jennings, Edited by Vaughan Lowe and Malgosia Fitzmaurice, Cambridge University Press, 1996, p.67.

22 TOMKA, P., "Custom and the International Court of Justice", en The Law and Practice of International Courts and Tribunals 12 (2013), Martinus Nijhoff Publishers, p.215.

23 Ibid.

24 PELLET, A., "Shaping the Future in International Law: The Role of the World Court in Law-Making", in Looking to the Future-Essays on International Law in Honor of W. Michael Reisman, MartinusNijhoff, Leiden/Boston, 2010, p.1076; y pp. 1065-1083.

25 MENDELSON, M., "The International Court of Justice and the sources of international law" cit, p. 67. 
desacuerdo entre la doctrina y la práctica judicial internacional en torno al alcance y formación 0 , incluso, existencia del derecho consuetudinario, se ha caracterizado, como expone Kammerhofer, por "un alto grado de libertad en las 'soluciones' propuestas por académicos y jueces"26. Persisten las dudas respecto a la determinación de la cantidad de práctica estatal que es necesaria para constituir una "regularidad conductual" suficiente que conforme el elemento material, en tanto existe dificultad para argumentar a favor o en contra de la relevancia de actos y declaraciones como práctica estatal27.

En el Reporte Final "Statement of Principles Applicable to the Formation of General Customary International Law", de la International Law Association en la Conferencia de Londres, en el año 2000, no faltaba razón cuando se advertía, entre las dificultades para establecer las normas sobre este tema, que el derecho consuetudinario es, por su propia naturaleza, el resultado de un proceso informal de creación de reglas, y que suscita cuestiones controvertidas de la teoría y la ideología: "For instance, those who regard State sovereignty and sovereign will as the very roots of international law are more inclined to look for consent (manifest or imputed) in the customary process than those who take a less Statecentred stand point" 28 .

En cuanto a la identificación del derecho consuetudinario en la actuación del TPIY, en su momento Theodor Meron sostuvo que si una condena penal por violar el derecho consuetudinario no codificado debía conciliarse con el principio de legalidad debía ser mediante el uso de métodos claros y bien establecidos para identificar el derecho consuetudinario. Apuntó, además, que en contraste con otros tribunales internacionales, "international criminal tribunals have taken an essentially conservative and traditional approach to the identification and application of customary international law principles"29. Para éste, los miembros del TPIY habían superpuesto en el Estatuto la prueba de si cada uno de los crímenes dentro de las jurisdicciones del tribunal reflejan el derecho consuetudinario, aplicado no sólo a los crímenes específicamente recogidos como graves en el Convenio de Ginebra, llámese genocidio y crímenes contra la humanidad, sino también las violaciones de la leyes y costumbres de guerra que se mencionan en el artículo 3 del Estatuto.

26 KAMMERHOFER, J., "Uncertainty in the Formal Sources of International Law: Customary International Law and Some of Its Problems", EJIL (2004), vol. 15 no. 3, p. 551.

27 Ibid, pp. 551 y 552.

28 International Law Association London Conference (2000), Committee on formation of customary (General) International Law, Final Report of the Committee, Statement of Principles Applicable to the Formation of General Customary International Law, pp. 2 y 3.

29 MERON, T., "Revival of Customary Humanitarian Law", en AJIL, vol. 99, no. 4 (Oct., 2005), p. 821. 
Meron de esta forma sostenía que: "(s)pecifically, and with rigor that has increased over the years, the chambers have engaged in a serious search for state practice and opinio juris" 30.

Sin embargo, no es posible aceptar y suscribir plenamente esta afirmación. El propio Meron tuvo que rendirse igualmente ante la evidencia de un Tribunal que, en ocasiones, ha reconocido un principio como derecho consuetudinario sin tener constancia específica de la práctica de los Estados y de la opinio juris, aunque en su consideración en esas ocasiones se justificaba porque estaba claramente establecido en el tiempo en que se cometieron los hechos $^{31}$. En realidad, el TIPY tuvo diferentes aproximaciones y diversas metodologías para indicar cuando una norma alcanzaba la naturaleza de consuetudinaria ${ }^{32}$. Este inconveniente hizo que algunos autores reclamaran cierta particularidad en los tribunales penales internacionales en el proceso de verificación de la práctica y la opinio iuris. A diferencia de otros tribunales que aplican el derecho internacional general, estos tribunales internacionales desarrollaron una labor marcada por un incontestable "activismo judicial" 33 En este plano, habría que tener en cuenta que la determinación de la "densidad" de la práctica para convertirse en norma consuetudinaria depende de la materia que se analice. Además, sería necesario analizar si estamos ante condiciones prohibitivas, obligatorias 0 permisivas ${ }^{34}$.

De este modo, son muchos los factores que influyen en los criterios para la determinación del derecho consuetudinario en el ámbito del Derecho Penal Internacional. Según Cassese, la dificultad que deriva de la naturaleza no escrita de las normas consuetudinarias, agravadas en una rama del Derecho Internacional como el Derecho Penal internacional, con un "rudimentario" cuerpo de normas jurídicas, hace que los Tribunales tengan un importante rol en la construcción de esta rama del derecho, muy parecido a los sistemas del common law a través del "precedente judicial"35. Todo ello tuvo como trasfondo, en el caso específico del TPIY, la parquedad

\footnotetext{
30 Ibid.

${ }^{31}$ Ibid, pp. $817-834$ y p. 823.

32 ARAJÄRVI, N., The Changing Nature of Customary International Law. Methods of interpreting the concept of custom in international criminal tribunals, RoutledgeCavendish, Taylor \& Francis Group, London and New York, p. 117.

33 SCHABAS, W.A., The Legal Regime of the International Criminal Court, Essays in Honour of Professor Igor Blishchenko, Edited by José Doria, Hans-Peter Gasser, M. Cherif Bassiouni, Martinus Nijhoff Publishers, Leiden-Boston, 2009, p.100. Ver igualmente a SCHACK, M., KJELDGAARD-PEDERSEN, A., "Striking the Balance between Custom and Justice-Creative Legal Reasoning by International Criminal Courts", en International Criminal Law Review, 16 (2016), pp. 913-934.

34 HENCKAERTS, J.M., "Customary International Humanitarian Law: a response to US comments", International Review of the Red Cross, Volume 89 Number 866 June 2007, pp. 475 y 476.

35 Cfr., CASSESE, A., International Criminal Law, Second Edition, Oxford University Press, 2008, p. 17.
} 
en los artículos de los Estatutos, que hizo necesario apoyarse en el derecho consuetudinario para extenderse a áreas que normalmente no estaban cubiertas por la práctica de los Estados en el derecho internacional público, o a una opinio juris correspondiente, como los modos de responsabilidad en procesos penales, la aplicación de las defensas (por ejemplo, coacción) en el marco de la responsabilidad penal individual, etc. ${ }^{36}$

El rol de las decisiones judiciales, consideradas como medios subsidiarios por el Estatuto de la Corte Internacional de Justicia en su artículo 38 (1) (d), alcanza en el Derecho Penal Internacional una importancia enorme. Por un lado, constatan si una norma consuetudinaria ha evolucionado; y, por otro lado, sirven como medio para establecer la interpretación más apropiada para ser incluida en una norma de tratado37. En este punto, en el asunto Kupreškić el TPIY reconoció la importancia de las decisiones judiciales o la legislación nacional en la determinación de los principios generales de derecho penal comunes a los mayores sistemas del mundo y en la determinación del derecho consuetudinario en la labor del Tribunal ${ }^{38}$. Aunque sostendría, en este mismo caso, que las decisiones judiciales de los Tribunales Internacionales serían utilizadas como "medios subsidiarios en la determinación de las normas de derecho", como expresa el artículo 38(1)(d) del Estatuto de la Corte Internacional de Justicia -y rechaza la idea de que la fuerza vinculante de las decisiones de la Cámara de Apelaciones del Tribunal sobre los Salas inferiores, y de aquellos de otros Tribunales internacionales con respecto al TPIY, se encuadren en la doctrina del precedente judicial (stare decisis) de los países del common law-, ${ }^{39}$. Sin embargo, no deja de reconocer que " $(\mathrm{m})$ ore specifically, precedents may constitute evidence of a customary rule in that they are indicative of the existence of opinion iuris sive necessitatis and international practice on a certain matter, or else they may be indicative of the emergence of a general principle of international law" 40 .

Ahora bien, es necesario insistir que el movimiento del TPIY se tornó inconsistente, a veces poco convincente, en la identificación del derecho consuetudinario. En algún caso, llevó a cabo la búsqueda de normas consuetudinarias, ya sea como opinio juris o como práctica de los Estados, mediante un proceso que, al decir de Schabas, parecía tautológico, porque lo llevaba de regreso a una de las fuentes

\footnotetext{
36 STAHN, C., y VAN DEN HERIK, L., "Fragmentation', Diversification and '3D' Legal Pluralism: International Criminal Law as the Jack-in-the-Box?", en The Diversification and Fragmentation of International Criminal Law (Edited by Larissa van den Herik and Carsten Stahn), MartinusNijhoff Publishers, Leiden-Boston, 2012, p. 62.

37 CASSESE, A., International Criminal Law, cit., pp.26 y 27.

38 Prosecutor v. Kupreškić et al., Judgment, Trial Chamber, Case. IT-95-16-T, T.Ch., 14 January 2000, párrafo 537.

${ }^{39}$ Ibid, párrafos 540 a 542.

$40 \mathrm{Ibid}$, párrafo 540.
} 
primarias, como las convenciones ${ }^{41}$. En buena medida ello se corrobora con la aplicación de las Convenciones de Ginebra de 1949 y sus Protocolos Adicionales de 1977, que el Tribunal destacaba como ejemplos notables de Convenciones que contenían el derecho internacional consuetudinario ${ }^{42}$. Por tal razón en el asunto Kordić, la Cámara de Apelaciones sostuvo que: "The maxim of nullum crimen sine lege is also satisfied where a State is already treaty-bound by a specific convention, and the International Tribunal applies a provision of that convention irrespective of whether it is part of customary international law"43.

\section{4.- ALGUNOS EJEMPLOS DE LOS ENFOQUES EN LA IDENTIFICACIÓN DEL DERECHO CONSUETUDINARIO POR EL TPIY}

Son muchos los ejemplos de los diferentes enfoques en la determinación del derecho consuetudinario por este Tribunal, pero por problemas de espacios resaltaron algunos que fueron importantes. En la Decision of the Defence Motion for Interlocutory Appeal on Jurisdiction del asunto Tadić, 44 hubo pronunciamientos importantes en torno al derecho consuetudinario. La Cámara de Apelaciones tuvo que resolver dos cuestiones medulares de la jurisdicción de este Tribunal. En primer lugar, valoró si el artículo 3 del Estatuto, referido a las "leyes y costumbres de la guerra" era de aplicación a los conflictos armados de carácter internacional y/o de carácter interno. El artículo no especificaba este aspecto y los apelantes argumentaron que la jurisdicción del Tribunal estaba limitada a las violaciones que se produjeran en el contexto de un conflicto armado. En segundo lugar, y relacionado con lo anterior, se preguntó si era posible, en consecuencia, establecer la responsabilidad penal de personas por estas violaciones en el contexto de un conflicto armado interno.

\footnotetext{
${ }^{41}$ SCHABAS, W.A., The Legal Regime of the International Criminal Court, cit, p. 80. 42 Prosecutor v. Tadić, Decision of the Defence Motion for Interlocutory Appeal on Jurisdiction, IT-94-1, 2 October 1995, para.98. Meron, quien tendría un rol importantísimo en la vida del TPIY, destacaba el carácter consuetudinario de las Convenciones de Ginebra en un artículo muy temprano. MERON, T., "The Geneva Conventions as Customary Law", AJIL, vol. 81, no. 2., 1987), pp. 348-370.

43 Prosecutor v. Dario Kordić and Mario Čerkec, Judgement, Appeals Chamber, Case No. IT-95-14/2-A, 17 December 2004, párrafo 44.

44 Prosecutor v. Tadić, IT-94-1, 2 October 1995, cit, párrafos 96-137. El asunto Tadić "was an enthusiastic but relatively low-level participant in the crimes that occurred in Bosnia in the early 1990s, and he was available for trial at the ICTY at a time when it suffered from both a lack of individuals to try and a surfeit of judges with no cases to adjudicate", MARSTON DANNER, A., MARTINEZ, J.S., "Guilty Associations: Joint Criminal Enterprise, Command Responsibility, and the Development of International Criminal Law", California Law Review, vol. 93, Issue 1 Article 2, 2005, p. 104.
} 
En torno al primer punto, entre las razones que brindó la Cámara para considerar que este artículo del Estatuto era de aplicación tanto a los conflictos armados de carácter internacional como a los conflictos armados de carácter interno, se encontraba la "emergence of international rules governing internal strife"45. Ésta pretendió encontrarlo en el derecho consuetudinario y en las disposiciones de Tratados, como el artículo 3 común de las Convenciones de Ginebra de 1949, en el artículo 19 de la Convención de la Haya para la Protección de la Propiedad en caso de conflicto armado de 14 de mayo de 1954, así como en el Protocolo Adicional de 1977, cuya interacción con el derecho consuetudinario era tal "that some treaty rules have gradually become part of customary law"46. Sin embargo, antes de indicar aquellos principios y normas de derecho consuetudinario que habían cristalizado en la comunidad internacional con el objetivo de regular un conflicto civil, indicó las dificultades para constatar la práctica de los Estados en los conflictos armados internos, en tanto "it is difficult, if not impossible, to pinpoint the actual behaviour of the troops in the field for the purpose of establishing whether they in fact comply with, or disregard, certain standards of behaviour"47. Por lo cual, la formación de las normas y principios consuetudinarios solamente habría que encontrarlos en los pronunciamientos oficiales de los Estados, los manuales militares y las decisiones judiciales ${ }^{48}$.

En cuanto al segundo punto, los apelantes consideraban que, si aun el derecho consuetudinario incluía principios básicos aplicables tanto a los conflictos armados internacionales como internos, tales prohibiciones no entrañaban una responsabilidad internacional individual cuando los crímenes eran cometidos en un conflicto armado interno. Esto encontraba un indudable apoyo en que el artículo 3 común de las Convenciones de Ginebra no contenía referencia a la responsabilidad penal por la violación de tales prohibiciones. Sin embargo, la Cámara consideró un razonamiento correcto el realizado por el Tribunal de Núremberg, que concluyó que la ausencia de disposiciones en los Tratados sobre el castigo de crímenes graves no impedía establecer responsabilidad penal individual, y no tenía dudas que las violaciones comprendidas en el artículo 3 conllevaban responsabilidad penal, ya fueran cometidas en un conflicto armado internacional 0 interno. En este caso, "(p)rinciples and rules of humanitarian law reflect "elementary considerations of humanity" widely recognized as the mandatory minimum for conduct in armed conflicts of any kind", de modo que "(n)o one can doubt the gravity of the acts at issue, nor the interest of the international community in

\footnotetext{
45 Prosecutor v. Tadić, IT-94-1, 2 October 1995, cit, párrafo 98.

46 Ibid.

47 Ibid, párrafo 99.

48 Ibid.
} 
their prohibition"49. Como elementos de práctica estatal en este sentido, mencionó la intención por parte de algunos Estados de criminalizar violaciones de normas y principios consuetudinarios en conflictos armados, como durante la guerra civil en Nigeria; también hizo mención a Manuales Militares de Alemania, Nueva Zelanda, Estados Unidos y Gran Bretaña; recordó el Código Penal de la República Federal Socialista de Yugoslavia de 1990, que tuvo el propósito de aplicar a nivel nacional algunos crímenes recogidos en las Convenciones de Ginebra; también a una ley belga de 1993 para implementar las mencionadas convenciones y sus protocolos adicionales ${ }^{50}$; y como aspecto relevantes de la opinio iuris, la Cámara se apoyó en Resoluciones del Consejo de Seguridad aprobadas para el caso de la guerra civil en Somalia, donde condenó las violaciones del Derecho Internacional humanitario y expresó que los autores de tales violaciones o los que ordenaron cometerlas, serían responsables individualmente por tales hechos 51 .

A juicio de la Cámara "(a)ll of these factors confirm that customary international law imposes criminal liability for serious violations of common Article 3, as supplemented by other general principles and rules on the protection of victims of internal armed conflict, and for breaching certain fundamental principles and rules regarding means and methods of combat in civil strife"52. A esto agregó un elemento importante, en tanto esta posibilidad de responsabilidad también se sustentaba "from the point of view of substantive justice and equity" 53 . Sin nada más que justificara el establecimiento del derecho consuetudinario, con tan pocos elementos de práctica estatal y de opinio iuris, era lógico que desde el inicio la metodología para identificar el derecho consuetudinario por este Tribunal tuviera grandes dosis de creatividad judicial. Algunos autores de peso en este sentido consideraron que parecía prematuro que en 1995, con base en la práctica, pudiera sostenerse que el principio de responsabilidad penal individual por crímenes de guerra cometidos en conflictos armados no internacionales fuera habitual ${ }^{54}$.

Sobre esta base, el TPIY en el asunto Hadžihasanović determinó que el concepto de "responsabilidad de comando", hasta ese momento derecho internacional consuetudinario en relación con los crímenes de guerra cometidos en el curso de un conflicto armado internacional, se aplicaba igualmente a las infracciones de las mismas prohibiciones cuando se cometían en el curso de un conflicto armado interno. La Sala concuerda lo incorrecto de suponer que, de

\footnotetext{
49 Ibid, párrafo 129.

50 Ibid, párrafo 130-132.

51 Ibid, párrafo 133.

52 Ibid, párrafo 134.

53 Ibid, párrafo 135.

54 HENCKAERTS, J.M., "Civil War, Custom and Cassese", Journal of International Criminal Justice, 10 (2012), p. 1101.
} 
conformidad con el derecho internacional consuetudinario, todas las normas aplicables a un conflicto armado internacional se apliquen automáticamente a un conflicto armado interno, pues en todo caso "to hold that a principle was part of customary international law, it has to be satisfied that State practice recognized the principle on the basis of supporting opinio juris". Sin embargo, la Cámara ofreció un grupo de argumentos en el siguiente sentido: si la realización de ciertos actos en el curso de un conflicto armado interno estaban impuestas por el artículo 3 común a los Convenios de Ginebra de 1949, y el derecho internacional consuetudinario incluía el concepto de "responsabilidad de mando" en relación con los crímenes de guerra cometidos en el curso de un conflicto armado internacional, era difícil "to see why the concept would note qually apply to breaches of the same prohibitions when committed in the course of an internal armed conflict" 55 .

Sobre la base de distinguir entre "responsable command" y su corolario "command responsibility", la Cámara sostiene que la posición no es diferente en los conflictos armados internos, pues el "responsable command" era una noción integral de la prohibición impuesta por el artículo 3 común a los Convenios de Ginebra de 1949 contra la realización de ciertas actos en el curso de un conflicto armado interno. En este sentido, sostiene que si el artículo 3 del Estatuto se refiere a crímenes de guerra cometidos en el curso de un conflicto armado internacional o a crímenes de guerra cometidos en el curso de un conflicto armado interno en virtud del artículo 3 común a los Convenios de Ginebra, suponía que había un fuerza militar organizada y, por lo tanto, era evidente "that there cannot be an organized military forcesave on the basis of responsible command", del mismo modo que "It is also reasonable to hold that it is responsable command which leads to command responsibility" 56 .

En todo caso, no se encuentran ejemplos de práctica estatal que sostengan este requisito recordado por la Cámara y se llega a reconocer que "it is true that, domestically, most States have not legislated for command responsibility to be the counter part of responsable command in internal conflict" ${ }^{\prime 57}$. Ello no impide decir a la Cámara que esto "does not affect the fact that, at the international level, they have accepted that, as a matter of customary international law, relevant aspects of international law (including the concept of command responsibility) govern the conduct of an internal armed conflict, though of course not all aspects of international law apply. The relevant aspects of international law unquestionably regard a military force engaged in an internal armed conflict as organized and

55 Decision on Interlocutory Appeal Challenging Jurisdiction in Relation to Command Responsibility ('Decision on Command Responsibility'), Hadžihasanović et al. (IT01-47-AR72), Appeals Chamber, 16 July 2003, párrafo. 16.

${ }^{56} \mathrm{Ibid}$, párrafo 13.

57 Ibid, párrafo 17. 
therefore as being under responsible command. In the absence of anything to the contrary, it is the task of a court to interpret the underlying State practice and opinio juris (relating to the requirement that such a military force be organized) as bearing its normal meaning that military organization implies responsible command and that responsible command in turn implies command responsibility" 58 . No obstante, como expresara Greenwood sobre este asunto, y con el que coincidimos, "the ICTY is by no means the only international law or tribunal whose application of the test that is lays down for the establishment of customary international law is not a rigorous as the way in which those tests are formulated might lead one to expect. Moreover, it is probable that most states would accept the concept of command responsibility as part of the law applicable to noninternational armed conflicts. Nevertheless, as with the jurisdiction decision in Tadić, one is left with the feeling that the Tribunal is painting with a fairly broad brush when it comes to the establishment of customary law, particularly with regard to non-international conflicts" 59 .

En la configuración, alcance y definición de los crímenes internacionales, con impactos mucho más directos con el principio de legalidad, se evidenció criterios para la identificación que no en todos los casos apelaba a la práctica estatal y a la opinio iuris. Ello desembocó en diversas interpretaciones y soluciones encontradas en puntos determinantes. En lo tocante al "crimen contra la humanidad" en el asunto Tadić se encuentra un momento importante. Luego de considerar el carácter consuetudinario del "crimen contra la humanidad"60, y entre sus requisitos la existencia de un conflicto

\footnotetext{
${ }^{58}$ Ibid.

59 GREENWOOD, C., "Command Responsibility and the Hadžihasanović Decision", Journal of International Criminal Justice, 2, (2004), 598-605, p. 602.

60 El Tribunal considera que el término "crímenes de lesa humanidad", aunque no codificado previamente, se había utilizado en un sentido no técnico desde 1915 y en posteriores declaraciones relativas a la Primera Guerra Mundial y se insinuó en el preámbulo de la Convención de La Haya de 1907 en la llamada "Cláusula Martens". De este modo, se incluye en el Artículo 6 (c) de la Carta de Núremberg, en la Carta del Tribunal Militar Internacional para el Lejano Oriente del 19 de enero de 1946 ("Carta de Tokio") y en la Ley no. 10 del Consejo de Control para Alemania ("Ley del Consejo de Control No. 10"), que se utilizaron para enjuiciamientos adicionales por atrocidades cometidas durante la Segunda Guerra Mundial. La prohibición de crímenes de lesa humanidad sería afirmada posteriormente por la Asamblea General en su resolución titulada "Afirmación de los principios del derecho internacional reconocida por la Carta del Tribunal de Núremberg" y posteriormente confirmada en los Principios de Derecho Internacional Reconocidos en la Carta del Tribunal de Núremberg y en la Sentencia del Tribunal ("Principios de Núremberg"), adoptados por la Comisión de Derecho Internacional en 1950 y sometidos a la Asamblea General. Prosecutor v. Tadić, Opinion and Judgment, Trial Chamber, Case No. IT-94-1-T, 7 May 1997, párrafos.618-623. De modo enfático expresaría: "There is no question but that crimes against humanity form part of customary international law. They found expression in Article 6(c) of the Nuremberg Charter of 8 August 1945, Article II(1)(c) of Law No. 10 of the Control
} 
armado (hace la distinción entre "ataque" y "conflicto armado"61), indica igualmente que los actos podían realizarse de forma generalizada o sistemática contra una población civil. Para encontrar apoyo de que los requisitos de "generalizada" o "sistemática" son alternativas, se auxilia en la Vukovar Hospital Decision del propio TPIY, en el Informe del Comité Ad Hoc sobre el establecimiento de la Corte Penal Internacional Permanente, y en el artículo 18 de la Comisión de Derecho Internacional sobre el proyecto de Código de Crímenes contra la Paz y la Seguridad de la Humanidad ("Proyecto de Código de la ILC") que hace mención a la jurisprudencia inmediatamente posterior a la Segunda Guerra Mundial, sobre todo de los tribunales estadounidenses y los tribunales en la Zona británica, así como posteriores casos de cortes nacionales ${ }^{62}$. En igual sentido, señaló la posibilidad de su comisión por razones puramente personales $^{63} \mathrm{y}$, en tal sentido, asume el case law como la única evidencia de derecho consuetudinario ${ }^{64}$. Para concluir que todos los crímenes de lesa humanidad no presuponían una intención discriminatoria, toma en cuenta "both judicial practice and possibly evidence of consistent State practice, including national legislation", para demostrar si el derecho consuetudinario se había desviado del derecho convencional al adoptar una noción más restringida de los crímenes de lesa humanidad, que ubica en el artículo 6 (c) del Acuerdo de Londres de 8 de agosto de 1945, en el Artículo 5 c del Estatuto del Tribunal Internacional de Tokio, en el Artículo II (1) (c)) de la Ley del Consejo de Control No. 10. En tal sentido, el derecho consuetudinario lo identifica a partir de la jurisprudencia nacional, el Proyecto de Código de Delitos contra la Paz y la Seguridad de la Humanidad de la Comisión de Derecho Internacional, y el documento preparatorio del Comité para el Establecimiento de una Corte Penal Internacional, donde se sostiene que el Artículo 7 del Estatuto de

Council for Germany of 20 December 1945 and Article 5(c) of the Tokyo Charter of 26 April 1946, three major documents promulgated in the aftermath of World War II", Prosecutor v. Tadić, Decision on the Defence Motion on Jurisdiction, 10 August 1995, párrf. 76.

61 El Tribunal consideró que el "ataque" sobre la población civil y "el conflicto armado"- deben ser conceptos separados, aunque, por supuesto, en virtud del artículo 5 del Estatuto, el ataque contra "cualquier población civil" puede ser parte de un "conflicto armado". Sin embargo, se requiere un nexo con los actos del acusado solo para el ataque contra "cualquier población civil". No se requiere un nexo entre los actos del acusado y el conflicto armado. El requisito de conflicto armado se satisface con la prueba de que hubo un conflicto armado; eso es todo lo que requiere el Estatuto, y al hacerlo, requiere más que el derecho internacional consuetudinario. Prosecutor v. Tadić, IT-94-1-A, 15 July 1999, cit, párraf.251; también en Prosecutor $v$. Dragoljub Kunarac et.al, IT-96-23\& IT-96-23/1-A, 12 June 2002, cit, párrafo 86.

62 Prosecutor v. Tadić, IT-94-1-T, 7 May 1997, cit, párrafos 647-549.

63 Prosecutor v. Tadić, IT-94-1-A, 15 July 1999, cit, párrafo 255.

64 Ibid, párrafo 257. 
Roma encarna el rechazo de los redactores de la intención discriminatoria 65 .

En igual medida, el asunto Kupreškić es un ejemplo notable de un rechazo abierto a apelar a los requisitos de la práctica y la opinio iuris para la identificación del derecho consuetudinario. La Sala de inicio entendió que las represalias contra los civiles, en virtud del derecho internacional consuetudinario, estaban prohibidas mientras los civiles se encontraran en las manos del adversario. Con respecto a civiles en zonas de combate, las represalias contra ellos estaban prohibidas por el artículo 51 (6) del Primer Protocolo Adicional de 1977, mientras que las represalias contra objetivos civiles estaban prohibidas por el artículo 52 (1) del mismo instrumento. Sin embargo, la Sala se encontró ante la pregunta sobre si estas disposiciones, suponiendo que no fueran declaratorias de derecho internacional consuetudinario, se habrían transformado en normas generales de derecho internacional, o como la propia Sala dice, si aquellos Estados que no han ratificado el Primer Protocolo, como EE. UU., Francia, India, Indonesia, Israel, Japón, Pakistán y Turquía, estaban obligados por reglas generales que tuvieran el mismo significado que esas dos disposiciones. La Sala en este punto asumió que no parecía haber surgido un cuerpo de práctica estatal que apoyara consistentemente la propuesta de que uno de los elementos de la costumbre, es decir, el usus hubiera tomado forma. Y es aquí donde el Tribunal se descolgó de las posiciones establecidas y razonó: "This is however an area where opinion iuris sive necessitatis may play a much greater role than usus, as a result of the aforementioned Martens Clause. In the light of the way States and courts have implemented it, this Clause clearly shows that principles of international humanitarian law may emerge through a customary process under the pressure of the demands of humanity or the dictates of public conscience, even where State practice is scant or inconsistent. The other element, in the form of opinion necessitatis, crystallising as a result of the imperatives of humanity or public conscience, may turn out to be the decisive element heralding the emergence of a general rule or principle of humanitarian law"66.

Sin lugar a dudas fue una opinión respetable y a la que difícilmente puedan oponerse cuestionamientos en su sentido, pues como expresó la propia Corte, si bien la Cláusula Martens ${ }^{67}$ no significa que los "principios de humanidad" y los "dictados de la consciencia pública" se han elevado a rango de una fuente independiente del Derecho internacional, en cualquier momento una norma de derecho internacional humanitario, no suficientemente

65 Ibid, párrafos 287-292.

66 Prosecutor v. Kupreškić et al., cit, párrafos. 527.

67 Sobre la Cláusula Martens ver: MERON, T., "The Martens Clause, Principles of Humanity, and Dictates of Public Conscience", AJIL, vol. 94, n. 1 (Jan., 2000), pp. 78-89. 
rigurosa o precisa, debe definir el alcance y propósito de esta norma con referencia a estos principios y dictados ${ }^{68}$. Sin embargo, esto muestra un proceso divergente en grado sumo en el proceso de identificación del derecho consuetudinario, determinado por conceptos loables y de incuestionable valor, pero que introducen un estado de notable inseguridad para lograr una plena identificación de un método de identificación que sea congruente con el principio de legalidad en el derecho internacional. En este mismo punto, a partir de no abandonar el criterio de la práctica en la determinación del derecho consuetudinario, un estudio de la CICR concluyó que: "Because of existing contrary practice, albeit very limited, it is difficult to conclude that there has yet crystallised a customary rule specifically prohibiting reprisals against civilians during the conduct of hostilities. Nevertheless, it is also difficult to assert that a right to resort to such reprisals continues to exist on the strength of the practice of only a limited number of States, some of which is also ambiguous. Hence, there appears, at a minimum, to exist a trend in favour of prohibiting such reprisals"69.

\section{LAS CONSECUENCIAS DE LOS DIFERENTES ENFOQUES EN LA IDENTIFICACIÓN DEL DERECHO CONSUETUDINARIO POR EL TPIY EN EL PRINCIPIO DE LEGALIDAD}

La garantía del respeto de los derechos humanos de presuntos responsables de crímenes, en nuestro caso crímenes internacionales, en los procesos penales que se abren en contra de éstos ante jurisdicciones nacionales 0 internacionales, tienen un soporte fundamental en el cumplimiento de varios principios básicos ${ }^{70}$. El

68 Prosecutor v. Kupreškić et al., cit, parraf.. 525. La Cámara de Apelaciones detalla como el TIJ, en Legality of the Threat or Use of Nuclear Weapons (Advisory Opinion), ICJ Reports 1996 , at p. 259, para. 84, sostuvo que había llegado a formar parte del derecho internacional consuetudinario, aunque en este caso la Cámara era del criterio que: "True, this Clause may not be taken to mean that the "principles of humanity" and the "dictates of public conscience" have been elevated to the rank of independent sources of international law, for this conclusion is belied by international practice", Prosecutor v. Kupreškić et al., cit, párrafo 525.

69 HENCKAERTS, J.M., DOSWALD-BECK, L., (eds), Customary International Humanitarian Law, Vol. I: Rules; Vol. II: Practice (ICRC and Cambridge University Press, 2005), p.523 y HENCKAERTS, J.M., "Civil War, Custom and Cassese" cit. 1009.

70 "The purposes of the principle of legality in criminal law can be divided into four sets. The first set includes the protection of individual human rights. The second promotes legitimacy of governance. These reasons justify including legality in the fundamental structure of government and of the international human rights system as an integral part of public international law. A third set suggests that legality in criminal law protects the structure of democratic (or even nondemocratic) governance by assigning lawmaking authority to the correct organ of government. This works differently in national and international criminal law. The fourth set pertains to promotion of the purposes of criminalization. Theses suggest that practicality aligns with morality on this issue, although counterarguments exist". 
principio de legalidad, en sus manifestaciones más conocidas, comporta que la responsabilidad sólo debe basarse en una prohibición de una conducta preexistente (nullum crimen sine lege), que a su vez conlleva la irretroactividad de la ley, además de otros requisitos indispensables, como que la prohibición penal de la conducta debe estar escrita (lex scripta) y los elementos del delito definidos de modo claro e inequívoco (lex certa), así como que no debe haber punición sin ley que la establezca (nulla poena sine lege) ${ }^{71}$. La adopción de la Declaración Universal de los Derechos Humanos por la Asamblea General de las Naciones Unidas en 1948, de numerosos Pactos Internacionales y Regionales -como el Pacto Internacional de los Derechos Civiles y Políticos, la Convención Europea y la Convención Americana de derechos humanos-, así como su incorporación a numerosos ordenamientos jurídicos internos, permitió que el "principio de legalidad" se convirtiera en un principio básico de derecho internacional consuetudinario ${ }^{72}$. Es cierto que el camino para su consagración en el orden internacional ha sido tortuoso, lleno de matizaciones y, en ocasiones, sin el rigor que lo caracteriza hoy día generalmente en los ordenamientos jurídicos nacionales de buena parte del mundo, cuando se advierten diversas interpretaciones en su aplicación práctica.

Entre 1945, final de la segunda guerra mundial hasta 1998, año del establecimiento del Estatuto de la Corte Penal internacional, el derecho penal internacional, arrastrando el fatigoso peso de la discusión entre la falta de lex scripta y su compatibilidad con el principio de legalidad, se movió, como hemos visto en el caso del TPIY, en los marcos de un gran "activismo judicial". Precisamente Núremberg confrontó la idea de una vulneración del "principio de legalidad" con la imperiosa necesidad de hacer justicia por la comisión de graves crímenes contra la paz y la humanidad, en un escenario carente de normas escritas y regidas fundamentalmente por el derecho consuetudinario de la época. De hecho, como recuerdan varios autores, el principio nullum crimen fue considerado, de una manera un tanto flexible, un principio de justicia que no debía impedir el castigo si la justicia así lo requería y ello provocó una deformación o "normativización" del nullum crimen, convirtiéndolo en

GALLANT, K.S., The Principle of Legality in International and Comparative Criminal Law, Cambridge University Press, 2009, pp. 19 y 20.

71 AMBOS, K., Treatise on International Criminal Law, vol. I: Foundations and General Part, Oxford University Press, pp.88 y 89; WERLE, G., Principles of International Criminal Law, T.M.C. Asser Press, 2005, pp. 32-34; GALLANT, K.S., The Principle of Legality cit, pp.11-12; CRYER, R., FRIMAN, H., ROBINSON, D., WILMSHURST, E., An Introduction to International Criminal Law and Procedure, second edition, Cambridge University Press, 2010, pp.17-21; CHERIF BASSIOUNI, M., Introduction to International Criminal Law cit, pp.246-253.

72 GALLANT, K.S., The Principle of Legality cit, pp.352-357. 
una máxima sustantiva de justicia que exige el castigo siempre que la justicia así lo requiera ${ }^{73}$.

En el citado informe del Secretario General, aprobado por el Consejo de Seguridad, se hacía un énfasis marcado en el derecho internacional humanitario, conformado tanto por reglas de carácter convencional como consuetudinarias, que tenía que tomar en cuenta el Tribunal para evitar la violación del principio de nullum crimen sine lege ${ }^{74}$. Aun cuando somos conscientes de las dificultades de una consistencia en el contenido de este principio, incluso por parte del propio TPIY ${ }^{75}$, al menos es conveniente trazar el contenido de análisis de aquellos pronunciamientos que concuerdan con los contenidos establecidos por la doctrina y el derecho consuetudinario de los derechos humanos, como aquella en el asunto Vasiljevic, que dejó bien claro: "under no circumstances may the court create new criminal offences after the act charged against an accused either by giving a definition to a crime which had none so far, thereby rendering it prosecutable and punishable, or by criminalising an act which had not until the present time been regarded as criminal"76.

El TPIY, si quisiéramos complementar esta idea, fue consciente de que tuvo que actuar conforme a las normas referidas a los derechos humanos consagradas en los instrumentos jurídicos internacionales en esta materia. Tanto es así que entendió que la exigencia de juzgamiento ante un tribunal imparcial "establecido por

\footnotetext{
73 AMBOS, K., Treatise on International Criminal Law, vol. I cit, p.75; Ver en un sentido amplio este problema en GALLANT, K.S., The Principle of Legality cit, pp.91-150.

74 Report of the Secretary-General Pursuant to Paragraph 2 of Security Council Resolution 808 (1993), S/25704 3 May 1993, United Nations, Security Council, p.9. 75 ARAJÄRVI, N., The Changing Nature of Customary International Law cit, pp. 120142.

76 Prosecutor v. Mitar Vasiljevic, cit, párrafo 196. El Tribunal se pronunció en el asunto Hadzihasanovic en torno a la exigencia de que el crimen establecido en una norma fuera accesible y previsible, de modo que la conducta en cuestión pudiera ser penalmente sancionada en el momento en que se cometió el crimen presuntamente. Entendió en cuanto a la previsibilidad, que la conducta en cuestión era la conducta concreta del acusado y debía poder apreciar que la conducta era criminal en el sentido generalmente entendido, sin referencia a ninguna disposición específica. Respecto a la accesibilidad, en el caso de un tribunal internacional como era ese tribunal, la accesibilidad no excluye la dependencia de una norma que se basa en la costumbre. Prosecutor v Enver Hadzihasanovic, Mehmed Alagic and Amir Kubara, Decision on Interlocutory Appeal Challenging Jurisdiction in Relation to Command Responsibility, 16 Jul 2003, .P.34. El TIPY en el asunto Vasiljevic expresaría: "the Trial Chamber must satisfy itself that this offence with which the accused is charged was defined with sufficient clarity under customary international law for its general nature, its criminal character and its approximate gravity to have been sufficiently foreseeable and accessible. When making that assessment, the Trial Chamber takes into account the specificity of international law, in particular that of customary international law. The requirement of sufficient clarity of the definition of a criminal offence is in fact part of the nullum crimen sine lege requirement, and it must be assessed in that context." Prosecutor $v$. Mitar Vasiljevic, cit, párrafo 201.
} 
la ley", recogida en el artículo 14, parágrafo 1 del Pacto Internacional de Derechos Civiles y Políticos, el artículo 6 (1) de la Convención Europea de derechos Humanos y Libertades Fundamentales y en el artículo 8 (1) de la Convención Americana de Derechos Humanos, era posible interpretarlo en el marco de un Tribunal Internacional como que "its establishment must be in accordance with the rule of law"77. Así, expuso que: "For a tribunal such as this one to be established according to the rule of law, it must be established in accordance with the proper international standards; it must provide all the guarantees of fairness, justice and even-handedness, in full conformity with internationally recognized human rights instruments"78. Pero desde el inicio, la aplicación en todos sus extremos del "principio de legalidad" en el Derecho Internacional penal encontró enormes desafíos. El carácter dinámico, enrevesado y poco uniforme en la conformación de las normas consuetudinarias, que hemos visto, juegan en contra de un principio que requiere estabilidad, certeza, previsión. Bassioni, por tal razón, divide en dos categorías los problemas que surgen con el derecho consuetudinario como fuente del Derecho Penal internacional: primero, la naturaleza misma de la costumbre como fuente del derecho internacional, es decir, su naturaleza vinculante en algunos o en todos los Estados y, en consecuencia, segundo, su aplicación espacial; y el carácter jurídico vinculante de la norma, su especificidad y la notoriedad que se le atribuye a efectos de atribución, ficción legal, presunción o incluso suposición de conocimiento de la ley por parte de aquellos a quienes se aplica supuestamente. En este caso reflexiona Bassioni que "(i)ndeed, customary international law cannot always satisfy the requirement of legality that applies to national criminal laws and therefore this source of ICl needs to be codified"79.

Por todas estas razones, en cuanto al principio de especificidad, Cassese sostiene que está muy lejos de ser completamente aplicable en el derecho internacional penal. Este autor pone como ejemplos la disposición que data de la Carta de Londres de 1945 y luego reformulada en otros instrumentos internacionales, como la Ley No. 10 del Consejo de Control, el Estatuto del Tribunal de Tokio, el Tribunal Penal Internacional para la ExYugoslavia, Tribunal Penal Internacional para Ruanda y otros, por el cual los crímenes contra la humanidad abarcaban "otros actos inhumanos"80. Del mismo modo cita de ejemplo las cuatro Convenciones de Ginebra de 1949 cuando enumera como violaciones graves la "tortura o tratos inhumanos", así como la existencia de nociones no definidas a nivel legislativo tales como "violación" (rape), "persecución" (persecution), "esclavitud" (enslavement), entre otros. A ello se suma que muchas de las

\footnotetext{
77 Prosecutor v. Tadić, IT-94-1, 2 October 1995 cit, párrafo 45.

78 Ibid.

79 CHERIF BASSIOUNI, M., Introduction to International Criminal Law cit, p. 251.

${ }^{80}$ CASSESE, A., International Criminal Law cit, p. 41.
} 
normas que prohíben conductas como criminales no especifican el elemento subjetivo del delito, ni existen normas claras de defensa en torno a las excusas o justificaciones en términos incuestionables en el ámbito de la defensa de los acusados ${ }^{81}$. Un ejemplo notable de la falta de especificidad, se encuentra en el artículo 3 del propio Estatuto, referido a las violaciones de "las leyes y costumbres de la guerra", en el que la Cámara de Apelaciones en Decision of the Defence Motion for Interlocutory Appeal on Jurisdiction del asunto Tadić, consideró que "the enumeration of some of these violations provided in Article 3 is merely illustrative, not exhaustive" 82.

Con este punto de partida, el TPIY tuvo que enfrentar un fenómeno muy complejo: cuando un nuevo crimen 83 aparecía, sus elementos estructurales, objetivos y subjetivos no estaban suficientemente claros ni tenía un marco penal sancionador establecido en las normas internacionales ${ }^{84}$. Eran crímenes que se enunciaban, en muchos casos, sin el rigor descriptivo de cualquier tipo penal como sí sucede en las legislaciones nacionales. Esto hizo que el TPIY tuviera varias tareas a la hora de solucionar un caso en los marcos del respeto al principio de nullum crime sine lege: entre ellas, estuvo obligado a asegurar que el delito incluido en el Estatuto era reconocido como tal por el derecho internacional consuetudinario en el momento en que se alegaba su comisión y, por tanto, que este delito era definido con suficiente claridad como para haber sido previsible y accesible, teniendo en cuenta la especificidad del derecho internacional consuetudinario ${ }^{85}$.

De modo que el TPIY, una vez considerado un determinado acto o conjunto de actos como delito, según el derecho internacional consuetudinario, debía cerciorarse de que ese delito imputado se había definido con suficiente claridad en virtud del derecho internacional consuetudinario por su naturaleza general, carácter criminal y su gravedad aproximada. ${ }^{86}$ En ocasiones, el TPIY fue muy enfático en el respeto del requisito de claridad suficiente en la definición de delito, de modo que si el derecho internacional consuetudinario no establecía una definición suficientemente precisa de un delito enumerado en el Estatuto, no tendría más opción que abstenerse de ejercer su jurisdicción, independientemente de que el

\footnotetext{
81 Ibid., p. 42. cit, pp. 245 y 246.

84 Ibid., p.4.

${ }^{85}$ Prosecutor v. Mitar Vasiljevic, cit, párraf. 198.

${ }^{86}$ Ibid, párraf. 201.
}

${ }^{82}$ Prosecutor v. Tadić, IT-94-1, 2 October 1995 cit, para. 87.

83 El TPIY, además de cumplir funciones muy parecidas a las que cumplen las Cortes en el sistema del common law, desarrolló el concepto dual de delito extendido en el ámbito del common law. En este se distingue entre "offence", es decir, entre los hechos que fundamentan la responsabilidad penal, compuesta de un aspecto externo (actus reus) y uno interno (mens rea), y del otro las circunstancias que excluyen la responsabilidad (defence). CASSESE, A., International Criminal Law 
crimen figure como un delito punible en el Estatuto. Como expresó el TPIY en asunto Vasiljevic: "This is so because, to borrow the language of a US military tribunal in Nuremberg, anything contained in the statute of the court in excess of existing customary international law would be a utilisation of power and not of law"87.

No podemos decir, sin embargo, que el TPIY pudo cumplir en todos sus extremos con esta exigencia. El Tribunal tuvo que hacer álgebra para delinear la estructura típica de los delitos recogidos en el Estatuto, a partir de una "asistemacidad" en los métodos para identificar el carácter consuetudinario de los elementos estructurales, y que sin lugar a dudas dejó ver la costura de sus debilidades. Tuvo que identificar principios donde la práctica internacional era escasa, construir fórmulas para dar solución a situaciones que difícilmente se habían encontrado en etapas pasadas, y ello, por supuesto, supuso un amplio margen de maniobra que intentó moverse entre la elaboración prudente y la vulneración de las garantías del acusado. Pero, en ocasiones, se desbordó por mucho cualquier contención, y se llegó en algún caso a identificar el derecho consuetudinario que sustentaba la condena de un delito sin definirlo. Ello aconteció en el asunto Kupreškić, cuando la Sala de primera instancia, consideró que el delito de persecución como una modalidad del crimen contra la humanidad bajo el artículo 5 (h) del Estatuto, "has never been comprehensively defined in international treaties" así como que "neither national nor international case law provides an authoritative single definition of what constitutes 'persecution"'88. En este punto concluía que la definición brindada en el asunto Tadić89, "is a broad definition which could include acts prohibited under other subheadings of Article 5, acts prohibited under other Articles of the Statute, and acts not covered by the Statute" 90 .

Ello dibujó un contexto adverso para el "principio de legalidad", pues en el mismo proceso donde se levantaban cargos contra un acusado, estaba presente la búsqueda de la definición de delito, su composición, y con la existencia, como trasfondo, de tantos métodos dispares para identificar esas claves o esos elementos determinantes en su configuración. Esta ausencia de rigor descriptivo en las normas consuetudinarias, llevó a que el Tribunal se debatiera en el proceso de interpretación sobre cuáles eran sus límites en su actividad judicial. En todo caso, teniendo la evidencia de la existencia de crímenes establecidos por el derecho consuetudinario con carácter previo, nada impedía, ni era contrario al principio de legalidad, que el Tribunal tuviera un margen de interpretación de los preceptos o normas a aplicar ya establecidos. En este punto la Cámara de

\footnotetext{
${ }^{87}$ Ibid, párraf. 202.

88 Prosecutor $v$. Kupreškić et al., cit , párrafo 567.

89 Prosecutor v. Tadić, Opinion and Judgment, Trial Chamber, Case No. IT-94-1-T, 7 May 1997, párrafos. 697, 710.

90 Prosecutor v. Kupreškić et al., cit, párrafo 617.
} 
Apelaciones del TPIY en el asunto Aleksovski, sostuvo en relación con el principio de legalidad: "That principle does not prevent a court, either at the national or international level, from determining an issue through a process of interpretation and clarification as to the elements of a particular crime; nor does it prevent a court from relying on previous decisions which reflect an interpretation as to the meaning to be ascribed to particular ingredients of a crime" ${ }^{\prime \prime 1}$.

En la práctica este proceso de clarificación, sin embargo, ha sido un poco más de lo que se enuncia. Porque los vaivenes e inconsistencias en la metodología para identificar el derecho consuetudinario inciden de manera notable en un proceso de "clarificación" que demanda sustentar la fuerza de su interpretación en el derecho consuetudinario. Ello supuso una "clarificación" que implicó restar o incorporar elementos al delito que encontraban sustento en el derecho consuetudinario. Una cuestión relacionada con este asunto tenía que ver con la posibilidad de interpretar los Estatutos de los Tribunales penales ad hoc, creados por resoluciones del Consejo de Seguridad, siguiendo las reglas de interpretación recogidas en la Convención de Viena de Tratados. El TPIY en el asunto Tadić había considerado que: "Although the Statute of the International Tribunal is a sui generis legal instrument and not a treaty, in interpreting its provisions and the drafters' conception of the applicability of the jurisprudence of other courts, the rules of treaty interpretation contained in the Vienna Convention on the Law of Treaties appear relevant" ${ }^{\prime \prime 2}$. En este orden, se ha dicho con razón que existe un conflicto potencial entre las normas consuetudinarias de interpretación de los tratados y los principios que deben aplicarse a la interpretación de un instrumento de derecho penal93. Aunque también se ha destacado con razón que el principio de in dubio pro reo matiza la cuestión, pues "in strict terms, the application of the principle in dubio pro reo should modify the application of the Vienna Convention methods of interpretation. This is because one of the limited reasons justifying reference to the preparatory work of a treaty is where the interpretation reached under Art. 31 'leaves the meaning ambiguous or obscure'"194.

La cuestión comenzó a tomar temperatura cuando se aludió a la capacidad de los Tribunales de "adaptar" disposiciones que prevén

91 Prosecutor v. Zlatko Aleksovski, Judgement, Appeals Chamber, Case No.: IT-9514/1-A, 24 March 2000, párraf.127; también ver a Prosecutor v. Delalić et.al., Judgment, Appeals Chamber, Case No.: IT-96-21-A, 20 February 2001, párraf. 173.

92 Prosecutor v. Dusko Tadić AKA "Dule", Decision on the Prosecutor's Motion Requesting Protective Measures for Victims and Witnesses, 10 Aug 1995, párraf. 18.

93 AKANDE, D., "Sources of International Criminal Law", en The Oxford Companion to International Criminal Justice, Editor-in-chief Antonio Cassese, Oxford University Press, 2009, p. 44, pp. 41-53.

94 Ibid. 
delitos a condiciones sociales cambiantes. El principio de no retroactividad de la ley estaría en el centro de la discusión sobre lo que se ha denominado una "adaptación expansiva" de algunos elementos jurídicos establecidos en normas internacionales a "nuevas condiciones sociales"95. En este punto Cassese llamó la atención sobre reconciliar el principio de no retroactividad con las características inherentes al Derecho Penal Internacional, en gran medida compuesto por normas consuetudinarias que a menudo se identifican, aclaran o explican, o se les da determinación jurídica por los tribunales ${ }^{96}$. A partir de sentencias de la Corte Europea de Derechos Humanos, Cassese llega a las siguientes conclusiones: mientras que la interpretación y clarificación de las normas existentes siempre es admisible, la adaptación sólo es compatible con principios jurídicos sujetos a requisitos estrictos. De modo que la extensión de los elementos jurídicos de un delito -como el actus reus- para cubrir una conducta que anteriormente no se consideraba claramente criminal debía: estar de acuerdo con las reglas de responsabilidad penal relacionadas con el tema, más específicamente con las normas que definen la "essence of the offence"; ajustarse, y de hecho implementar y actualizar principios generales del Derecho Internacional Penal o al menos principios generales del derecho; y ser razonablemente previsible para sus destinatarios, 0 en otras palabras, la extensión, aunque redunda en detrimento del acusado, debe ser previsiblemente anticipado por él, en consonancia con los principios de Derecho Penal ${ }^{97}$.

Si bien las Cortes no podían crear un nuevo delito, con nuevos elementos jurídicos (como nuevos actus reus o un nuevo mens rea) ellos podían sólo adaptar disposiciones que preveían delitos a condiciones sociales cambiantes, siempre que este ajuste estuviera en consonancia con, o incluso requerido por, principios generales. Ello quiere decir, en palabras de Cassese, que pueda resultar en una ampliación del actus reus o, posiblemente, en la reducción del umbral del elemento subjetivo, por ejemplo, desde la intención hasta la imprudencia, o desde la imprudencia hasta la culpabilidad ${ }^{98}$. Este proceso, que como sostiene Cassese, normalmente se dirige en detrimento del acusado, debe presuponer la existencia de una amplia prohibición penal y ninguna enumeración clara y explícita en la norma de los actos abarcados por esta definición. "It is the penumbra left by law around this definition that adaptation process and the analogical process, which is instead banned (...), is rather thin and porous. It falls to courts to proceed with great caution and determine on a caseby-case basis whether the 'adaptation' under discussion is legally

95 CASSESE, A., International Criminal Law cit, p. 44.

96 Ibid.

97 Ibid, p. 44-46.

98 Ibid, p. 46. 
warranted and consonat with general principles, and in addition does not unduly prejudice the rights of the accused"99.

En este mismo sentido, Thomas Meron y Mohamed Shahabudeen han marcado un debate sobre los límites permitidos en ese proceso de clarificación e interpretación y el principio de nullum crimen, sobre la base de la adaptabilidad de las normas jurídicas a las nuevas circunstancias. En el asunto Hadžihasanović donde ambos figuraron como jueces, la Cámara de Apelaciones tuvo posiciones encontradas en torno a si Amir Kubara, quien asumió el comando de una brigada del ejército de Bosnia en abril de 2003, podía ser responsables de las muertes y de la destrucción de la propiedad en Dusina ocurridas dos meses antes de que asumiera el cargo ${ }^{100}$. La Cámara no encontró ninguna práctica estatal ni opinio iuris que sostuviera la posibilidad de responder por tales crímenes, cometidos antes de que asumiera el mando de la brigada ${ }^{101}$. Sin embargo, de los jueces que integraban aquellas Cámara (Theodor Meron, Presidente, Fausto Pocar, Mohamed Shahabudeen, David Hunt y Mehmet Güney), se encontró la opinión disidente de dos de ellos, Hunt y Shahabudeen, quienes consideraron acertado extender el principio de la "responsabilidad por el comando" a los crímenes cometidos antes de la asunción del mando en el referido caso.

La opinión mayoritaria de la Cámara, no obstante fue conducente a rechazar esta posición:

"Unable to muster any significant evidence of State practice or opinio juris supporting their view, the dissenting Judges rely on a broad interpretation of treaty texts which do not address in terms the question of responsibility for crimes committed before the assumption of command. Their method is flawed. First, it represents a departure from our consistent jurisprudence requiring that criminal liability be grounded not only on statutory language but on firm foundations of customary law. Second, to interpret texts speaking of command responsibility as imposing a duty to punish, after the assumption of command, crimes committed before the assumption of command, is counterintuitive and contrary to the plain meaning of "command" responsibility. Although the duty to prevent and the duty to punish are separable, each is coterminous with the commander's tenure. Third, an expansive reading of criminal texts violates the principle of legality, widely recognized as a peremptory norm of international law, and thus of the human rights of the accused"102.

En un artículo posterior, Mohamed Shahabudeen matiza algunos de sus puntos de vistas respecto al principio de legalidad en

99 Ibid.

100 Decision on Interlocutory Appeal Challenging Jurisdiction in Relation to Command Responsibility ('Decision on Command Responsibility'), Hadžihasanović et al. (IT-01-47-AR72), Appeals Chamber, 16 July 2003, párrafo 38.

101 Ibid, párrafo 45.

102 Ibid, párrafo 55. 
el desarrollo del desarrollo del derecho internacional penal ${ }^{103}$. Una pregunta clave que se hace es si el requerimiento de especificidad del delito debe frenar el desarrollo progresivo del derecho internacional. Para ello hace alusión a la posibilidad de un caso en que no esté previamente regulado una condena para una conducta determinada, pero que cae dentro de implicaciones razonables de otro delito existente en el momento de la comisión del delito. La pregunta se redondea en si se violaría el principio de legalidad con una condena por esa conducta que equivalga a ese crimen ${ }^{104}$. Con apoyo en pronunciamientos de la Corte Europea de Derecho Humanos, Shahabudeen considera la posibilidad de que los tribunales desarrollen las normas adaptándolas a las circunstancias cambiantes ${ }^{105}$. Aunque reconoce que este proceso se parece más al seguido en el common law, ${ }^{106}$ estima que es posible que exista incluso en el derecho internacional penal. En tal sentido toma de ejemplo el caso de la Corte Europea de Derechos Humanos $C R \quad v$ United Kingdom, que también cita Cassese en su libro, en el que la Corte ante un recurso que sostenía la violación del artículo 7 de la Convención, (que establece que nadie sería considerado culpable de un delito con motivo de algún acto u omisión que no constituía delito según la ley nacional o internacional en la época en que fue cometido) convino en sostener que el "Article 7 (art. 7) of the Convention cannot be read as outlawing the gradual clarification of the rules of criminal liability through judicial interpretation from case to case, provided that the resultant development is consistent with the essence of the offence and could reasonably be foreseen"107.

Thomas Meron, en respuesta a este artículo, pone en duda cuán lejos esa idea de desarrollo subsiguiente de la norma es consistente con la "essence of the offence" y la previsibilidad. En relación concreta a la posición de los jueces disidentes en el asunto Hadžihasanović expresó que "more progressive approach to the analysis of customary international law embraced by the dissentsone that would affirmatively engage the criminal tribunal in the development of customary law, rather than simply in its applicationcannot be reconciled with the legality principle"108. Y en relación directa con la posición de Shadunbudden en el artículo apuntó que veía "a difference between removing personal immunity for liability for a obviously criminal act and extrapolating from it a theory of

103 SHAHABUDEEN, M., Does the Principle of Legality Stand in the Way of Progressive Development of Law? Journal of International Criminal Justice, 2 (2004), pp. 1007-1017.

104 Ibid p. 1011.

105 Ibid, p. 1012.

106 Ibid.

107 Case of S.W. v. The United Kingdom (Application no. 20166/92) Judgment, Strasbourg, 22 November 1995, párrafo 36.

108 MERON, T., "Revival of Customary Humanitarian Law; cit, p. 826. 
evolution and ex post facto application of criminal liability for acts that were not unlawfull at the time of their commission"109.

En nuestro caso, aun siendo conscientes de las enormes diferencias entre el derecho penal nacional y el derecho penal internacional ${ }^{110}$, un análisis en rigor de los derechos de las personas que están en juego con el "principio de legalidad", hace casi imposible que pueda sostenerse, en la forma en que se anuncia, su cumplimiento cabal en todos sus extremos, cuando precisamente el derecho consuetudinario es un componente fundamental del derecho a aplicar por estos tribunales. Consecuentemente la ausencia de normas escritas, que dependen en buena medida para su identificación de la labor intelectual del juez, es un rasgo típico de los sistemas asentados en el common law, que abre la puerta a considerar, o no, elementos jurídicos que antes no estaban -al adaptarse a "nuevas condiciones sociales-, y que implican, habría que decirlo así y en contraposición a lo que plantea Cassese, incorporar elementos jurídicos, que en buena medida suponen la aparición de nuevos delitos, o mejor, si se quiere, una reactualización de estos delitos vía judicial, si es que esto no lleva a la construcción o identificación de un "nuevo delito". ¿Cómo entender esto si no, ante aquellos casos en que el tribunal considera que por "nuevas condiciones cambiantes", un delito ha ampliado su actus reus, y no sólo exige dolo o intención sino también imprudencia? ¿Acaso no es ya una ampliación del marco de responsabilidad abarcable a otro tipo de conducta que antes no se contemplaba $y$, por ende, otro delito? ¿Acaso esta "reactualización", como hemos convenido en Ilamarla, no implica otras condiciones para establecer la responsabilidad del individuo, otras conductas punibles?

Por supuesto que otros muchos problemas estuvieron asociados al derecho consuetudinario como fuente de derecho para el TPIY. Los requisitos de previsibilidad y accesibilidad estuvieron más lejos de cumplirse -por lo menos con más fuerza el segundo- en un ordenamiento jurídico carente de normas escritas e identificables para cualquier de los acusados que fueron juzgados y condenados. Si

109 Ibid. Sin embargo, Meron sostiene que "a more relaxed approach to the identification of relevant customary norms may be justified where the norm in question does not concern the substantive scope of the criminal prohibition, or of the defendant's liability, and thus does not directly implicate the nullum crimen principle." Ibid, p.829. Como también pone de manifiesto Arajärvi, Noora: "He does not offer any further explanation or analysis on why the method of custom formation should be different in 'non-substantive scope of criminal prohibition or defendant's liability' than in the substantive matters, nor explanation on who is to determine when 'a more relaxed approach' could be resorted to." ARAJÄRVI, N., The Changing Nature of Customary International Law cit., p. 55.

110 Entre los aspectos relevantes a destacar entre ambos sistemas, como ya expresó Bassioni, se encuentra como difieren la aplicabilidad y la naturaleza vinculante de las fuentes, CHERIF BASSIOUNI, M., Introduction to International Criminal Law cit, p. 18. 
bien estamos de acuerdo que se pudiera apelar a la "conciencia pública" o a la "conciencia de la humanidad" como base para sostener un crimen como previsible, -que entendemos en la teoría penal como el conocimiento de la antijuricidad del hecho, requisito de la culpabilidad-, que en efecto no requiere para alguna doctrina penal nacional interesada, un "conocimiento exacto" del contenido de la norma infringida111. No encontraríamos la misma explicación en el cumplimiento del requisito de accesibilidad. Apelemos al sentido común: cómo pueden ser "accesibles" normas que a priori no deben conocer ni los jueces si son de aplicación al caso concreto -si tomamos en cuenta que dependen de un proceso de identificación, que apela a requisitos fijados doctrinalmente (como la práctica estatal y la opinio iuris)- y que debe resultar en la comprobación de lo que constituían derecho consuetudinario en el momento de la comisión de los hechos; cómo podía ser posible que estas normas hubieran sido "accesibles", normas que, a su vez, pueden "adaptarse" por conducto de la opinión de jueces a condiciones sociales cambiantes.

Pero si esto fue así, y se requiere que comprendamos para ese momento lógicas diferentes en la manera de entender el principio de legalidad, distintas a cómo se entiende el principio de legalidad en las legislaciones nacionales, y se denomina a este principio en el Derecho Penal internacional como un "principio sui generis"112, aun si ello vacía de contenido presupuestos fundamentales de este principio, entonces, a nuestro entender, se requeriría un modelo de contención del poder -en este caso de la comunidad internacional- que tuviera otros justificativos, por supuesto que serían menos garantistas, pero que no encontraran refugio en el "principio de legalidad", que para tales efectos y paradójicamente, se invocó con todos sus requisitos, sin desmedro de ninguno de ellos.

Esta "adaptabilidad" a situaciones cambiantes, como la necesidad de aceptar diferencias en la comprensión del principio de legalidad en el Derecho Penal internacional, son componentes que se combinan para mostrarnos un modelo de justicia internacional incapaz de garantizar en todos sus extremos los derechos y garantías que el derecho internacional de los derechos humanos ha consagrado en su dimensión convencional y consuetudinaria, no importa si son criminales del rango que lo eran ante el TPIY. No consideramos ni es posible aceptar, aun cuando entendemos las complejidades de este

111 Ver en la doctrina española a MUÑOZ CONDE, F., GARCÍA ARÁN, M., Derecho Penal, parte general, (8va.ed. revisada y puesta al día) Tirant lo Blanch, Valencia, 2010, pp. 381 y 382; ORTS BERENGUER, E., GONZÁLEZ CUSSAC, J.L., Compendio de Derecho Penal, Parte General (4ta.ed.), Tirant lo Blanch, Valencia, 2014. Ver en la doctrina alemana a ROXIN, Cl., Derecho Penal, Parte General, (trad. y notas Diego-Manuel Luzón Peña, Miguel Díaz y García Conlledo, Javier de Vicente Remesal), t. I, Madrid, Civitas, 1997, pp. 861-869.

112 Ver las opiniones sobre "diferencias estructurales" entre ambos ordenamientos jurídicos en: RAUTER, T., Judicial Practice, Customary International Criminal Law and Nullum Crimen Sine Lege, Springer, 2017, pp. 41-86. 
problema, "matices" o "contenidos propios" del "principio de legalidad" en el derecho internacional, bajo la excusa de un desarrollo "rudimentario" aun de su material normativo que era preciso acoplar, si estamos hablando de principios que precisamente se constituyeron en el desarrollo de la humanidad para oponerse a la arbitrariedad del poder. Pudiera decirse que estaban en juego en estos casos intereses mayores de la "comunidad internacional", que un interés superior de la humanidad justifica que esto sea así, y que se impusiera la justicia aun a costa de lacerar ciertos principios garantistas, pero para entonces cabría también reconocer, y dejar de buscar calificativos donde no caben, y readaptar principios que no lo permiten, que se hizo justicia y punto, sin los ropajes y la parafernalia del "principio de legalidad"; pero eso sí, habría que acotarlo, una justicia a toda costa.

\section{CONCLUSIONES}

Pese a la enorme trascendencia e importancia del TPIY para el desarrollo del derecho penal internacional, este Tribunal nació llevando en sí un peso enorme para cumplir sus funciones, entre la contención de la arbitrariedad por los Tribunales y la definición y la elaboración de las normas existentes. En todo ello, se advirtió una metodología inestable y "asistemática" en la identificación del derecho consuetudinario por este Tribunal, que impidió certeza, previsibilidad y representó importantes modificaciones en la comprensión del principio de legalidad como principio básico en la protección y garantía de los derechos humanos.

El abundante material legislativo a nivel internacional que pudo servir de soporte como única fuente no existía, y no podía pedírsele tampoco que lo fuera. La producción normativa en el Derecho Internacional tiene a los Estados como sus principales productores y éstos se debaten entre muchas contradicciones por intereses particulares y por visiones diferentes sobre el papel del orden internacional. Todo ello, tiene una incidencia negativa en una sector de ordenamiento jurídico escaso de práctica internacional continua y de legislación, paradójicamente obligado en su aplicación a respetar principios y derechos básicos del ser humano que sólo pueden llegar a serlos, en ocasiones, en circunstancias diametralmente opuestas. Aun así, la tarea de este Tribunal, que cierra sus puertas, fue de enorme trascendencia en la lucha contra la impunidad y tal vez falte todavía mucho por escribir sobre su impronta.

El examen de la práctica seguida por este Tribunal revela, en todo caso, que las cuestiones de derechos humanos tienen prioridad en el orden internacional pero que todavía interesa contar con los mecanismos precisos que hagan efectivo el goce de estos derechos. El principio de legalidad debe respetarse en todos sus extremos $y$, para ello, el ordenamiento jurídico internacional debe disponer de los pertinentes cauces. La interpretación judicial puede proporcionar 
fórmulas a través de las cuales no se produzca la impunidad pero, sin embargo, tiene también sus límites. Por ello, el avance más notable que se advierte en posiciones como la acogida por el TPIY en los asuntos analizados lo representa el esfuerzo porque el Derecho Internacional determine criterios nítidos en los supuestos de comisión de delitos que interesan a la comunidad internacional.

Ahora bien, la labor desarrollada por este Tribunal demuestra, una vez más, el "especial valor" que tiene la costumbre en el ordenamiento jurídico internacional, a diferencia de lo que sucede en los ordenamientos jurídicos internos. Las decisiones judiciales coadyuvan a determinar no sólo el valor de la costumbre sino, sobre todo, el contenido de las normas consuetudinarias vinculadas al sector relativo a la protección internacional de los derechos humanos. La eficacia de las normas en esta materia se determina, por lo tanto, en virtud de este procedimiento de creación de normas internacionales. Con ello, la incertidumbre que siempre aqueja a la costumbre internacional queda reducida, en razón de interpretaciones judiciales. EI TPIY ha proporcionada a la comunidad internacional, a través de sus sentencias, una base para que los derechos humanos reciban una idónea protección. 